\title{
Oxalate and calcium excretion in cystic fibrosis
}

\author{
M A Turner, D Goldwater, T J David
}

\begin{abstract}
Background-A patient with cystic fibrosis (CF) and repeated calcium oxalate renal stones prompted us to investigate other children for risk factors for this recognised complication of CF.

Methods-Twenty four hour urinary excretion of calcium, oxalate, and glycolate was measured in children with CF and no symptoms of renal tract stones. Normal diet and treatments were continued.

Results-In 26 children (aged 5-15.9 years) oxalate excretion was correlated with age; 14 of 26 children had oxalate excretion above an age appropriate normal range. There was a positive correlation between oxalate excretion and glycolate excretion. Mean calcium excretion was $0.06 \mathrm{mmol} / \mathrm{kg} / 24 \mathrm{~h}$ with 21 of 24 children having calcium excretion below the normal range.

Conclusions-Hyperoxaluria may reflect malabsorption although correlation between excretion of oxalate and glycolate suggests a portion of the excess oxalate is derived from metabolic processes. The hypocalciuria observed here may protect children with CF from renal stones.

(Arch Dis Child 2000;83:244-247)
\end{abstract}

Keywords: cystic fibrosis; oxalate; calcium; renal stones

Symptomatic calcium oxalate nephrolithiasis in patients with cystic fibrosis (CF) has been reported on several occasions. ${ }^{1-4}$ In a study of untimed postprandial urine collections in 43 patients with $\mathrm{CF}$ and no symptoms of urinary tract stone disease, mean urinary oxalate concentration in the whole patient sample was increased and mean urinary calcium excretion reduced. ${ }^{5}$ This report did not specify how many individual CF patients had altered urinary excretion of calcium or oxalate.

Microscopic nephrocalcinosis was observed

University

Department of Child

Health, Booth Hall

Children's Hospital, Charlestown Road,

Blackley, Manchester

M9 7AA, UK

M A Turner

D Goldwater

T J David

Correspondence to:

Dr M A Turner, Lecturer in Child Health, University

Department of Child Health,

St Mary's Hospital,

Hathersage Road,

Manchester M13 0JH, UK

email:

mark.turner@man.ac.uk

Accepted 10 March 2000 patients developed two calcium oxalate renal stones and this prompted us to examine the incidence in our patient population of two factors that could influence stone formation: urinary excretion of calcium and oxalate.

In this case CF had been diagnosed in infancy and was subsequently complicated by diabetes mellitus. The patient presented on two occasions with unilateral loin pain and frank haematuria. On each occasion (at 12 and 14 years) a calcium oxalate stone was passed. On the first occasion a 24 hour urine collection revealed an oxalate excretion of $0.99 \mathrm{mmol}$ per 24 hours (upper limit of normal at this age is $0.35 \mathrm{mmol}$ per 24 hours). On the second occasion an oxalate excretion of $1.11 \mathrm{mmol}$ per 24 hours was found. In addition, the glycolate excretion was found to be $0.46 \mathrm{mmol}$ per 24 hours (normal range $0.10-0.33 \mathrm{mmol}$ per 24 hours).

The aims of this study were: (1) to investigate the prevalence of hyperoxaluria in children with CF; (2) to ascertain whether hyperoxaluria could be attributed to metabolic causes by measuring glycolate excretion as a marker for precursors of oxalate; (3) to determine the level of calcium excretion; and (4) to relate the excretion of calcium and oxalate in each child in order to assess the likelihood of stone formation in this group.

\section{Patients and methods}

Twenty nine consecutive patients attending routine follow up appointments at the regional paediatric cystic fibrosis clinic at Booth Hall Children's Hospital, Manchester were approached about the study (total clinic population 100). Two of these patients declined to take part in the study. The remainder gave verbal consent to the 24 hour urine collection. All 27 children were pancreatic insufficient. Collections were carried at while the children were at home, on routine medication, but not on intravenous antibiotics. Children under the age of 5 years were not included; otherwise patients were unselected. Approval from the local ethics committee was not sought as the investigation involved was not invasive.

Subjects were asked to provide a 24 hour urine sample. The sample bottle contained 20 $\mathrm{ml}$ of $5 \mathrm{M}$ hydrochloric acid as acidic conditions would prevent metabolism of citrate to oxalate. In all cases the sample $\mathrm{pH}$ was less than 2.0, confirming adequate acidification. The volume of the 24 hour sample was determined by weighing. Two aliquots $(25 \mathrm{ml}$ and $10 \mathrm{ml}$ ) were stored at $-20^{\circ} \mathrm{C}$. Samples were batch processed in order to reduce variability.

Urine oxalate assays were performed using a high pressure liquid chromatography assay of a quinoline derivative with monitoring at bacterial colonisation that could lead to alterations in oxalate handling in patients with $\mathrm{CF}$ has recently been reported. ${ }^{10}$ One of our 
Table 1 Results of assays for oxalate, calcium, and glycolate

\begin{tabular}{|c|c|c|c|c|c|}
\hline Solute & $\begin{array}{l}\text { Minimum } \\
(\text { mmol/24 h) }\end{array}$ & $\begin{array}{l}\text { Maximum } \\
(\text { mmol/24 h) }\end{array}$ & $\begin{array}{l}\text { Mean } \\
(\text { mmol/24 h) }\end{array}$ & $S D$ & $\begin{array}{l}\text { Number } \\
\text { above normal }\end{array}$ \\
\hline \multirow[t]{3}{*}{ Oxalate $(n=26)$} & 0.26 & 1.03 & $<13 \mathrm{y}, \mathrm{n}=14,0.43$ & 0.17 & $14 / 26$ \\
\hline & & & $>13$ y $(M), n=7,0.66$ & 0.24 & \\
\hline & & & $>13 \mathrm{y}(\mathrm{F}), \mathrm{n}=5,0.44$ & 0.18 & \\
\hline \multirow[t]{2}{*}{ Glycolate $(n=25)$} & 0.015 & 0.71 & 0.232 & 0.16 & $2 / 25$ \\
\hline & $\begin{array}{l}\text { Minimum } \\
(\mathrm{mmol} / \mathrm{kg} / 24 \mathrm{~h})\end{array}$ & $\begin{array}{l}\text { Maximum } \\
(\mathrm{mmol} / \mathrm{kg} / 24 \mathrm{~h})\end{array}$ & $\begin{array}{l}\text { Mean } \\
(\mathrm{mmol} / \mathrm{kg} / 24 \mathrm{~h})\end{array}$ & $S D$ & $\begin{array}{l}\text { Number } \\
\text { below normal }\end{array}$ \\
\hline Calcium $(n=24)$ & 0.007 & 0.139 & 0.06 & 0.03 & $15 / 24$ \\
\hline
\end{tabular}

$310 \mathrm{~nm}$, according to a modification of the method of Koolstra et al. ${ }^{11}$ Ascorbate was removed prior to denaturation by solid phase extraction. All samples were assayed in duplicate together with aqueous standards containing 0.5 and $1.0 \mathrm{mM}$ oxalate.

Urine glycolate assays were performed according to the method of Kasides and Rose $\mathrm{e}^{12}$ by the biochemistry department at University College Hospital London. Interfering substances were removed by the addition of activated charcoal. Lactate contributes to the assayed products so the level of lactate was determined and taken into account. Urine calcium excretion was measured by atomic absorption spectroscopy at $515 \mathrm{~nm}$.

The following clinical data were collected for each patient from the clinical records: age, $\mathrm{FEV}_{1}$ corrected for height (expressed as a percentage of that expected for height), height (in $\mathrm{cm}$ and as a standard deviation score), weight (in $\mathrm{cm}$ and as a standard deviation score), body mass index (weight $/$ height $^{2}$ expressed as a standard deviation score), and lipase dose (units of lipase per kg per 24 hours). Standard deviation scores were calculated by the LSM method. ${ }^{13} 14$

The normal range for urinary concentration of oxalate after a 24 hour collection is dependent on the age and sex of the subject. In this laboratory normal concentrations in males and females under 13 years old are less than 0.35 mmol per 24 hours. For 13 years and over the upper range of normal for males is 0.48 $\mathrm{mmol} / 24 \mathrm{~h}$ and for females $0.52 \mathrm{mmol} / 24 \mathrm{~h}$. In this laboratory, normal amounts of glycolate excretion are at most $0.34 \mathrm{mmol} / 24 \mathrm{~h}$. Urinary calcium excretion was measured in 24 children. The normal range in this laboratory for

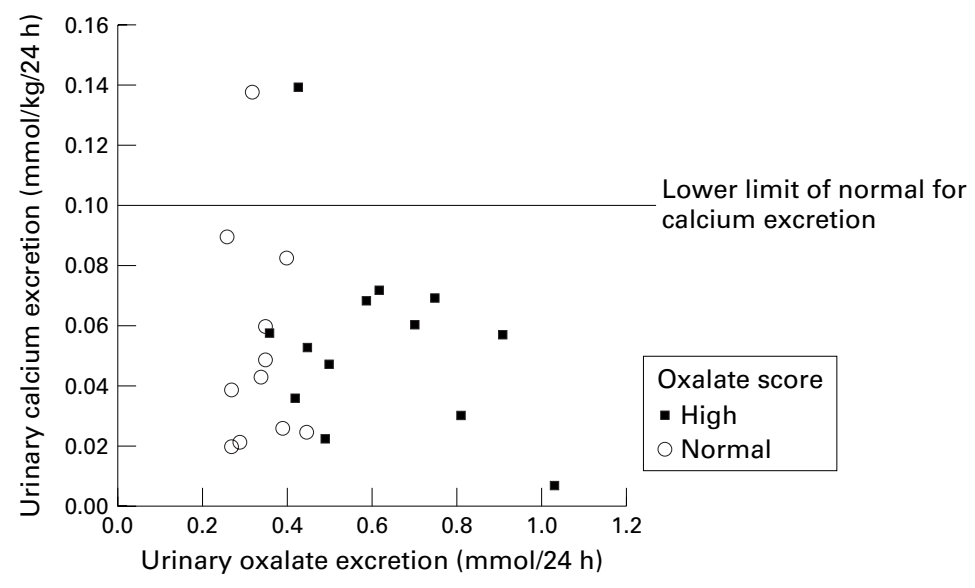

Figure 1 Urinary excretion of oxalate versus urinary excretion of calcium. this measurement is greater than $0.1 \mathrm{mmol} /$ $\mathrm{kg} / 24 \mathrm{~h}$ for children weighing less than $25 \mathrm{~kg}$ or $0.25-0.75 \mathrm{mmol} / 24 \mathrm{~h}$ in children weighing more than $25 \mathrm{~kg}$ and in adults.

The data were analysed using SPSS. Parametric tests were used for the continuous variables: all of these variables had a distribution not significantly different from a normal distribution as tested with a Kolmogorov-Smirnov test $(\mathrm{p}>0.1)$.

Twenty seven urine samples were collected over a two month period. One patient did not return the sample bottle. This gave 26 samples: 12 from boys, and 14 from girls. The patients' ages ranged from 5 years to 15.9 years (mean 11.8 years, SD 3.41). The height corrected $\mathrm{FEV}_{1}$ was available in 25 cases and ranged from $32 \%$ to $108 \%$ (mean $76 \%$, SD $19.9 \%$ ). Lipase dose varied from 2250 units/kg/day to 31300 units/kg/day (mean 16 900, SD 6960). Weight standard deviation score varied from -1.38 to 1.08 (mean -0.38 , SD 0.84). Height standard deviation score varied from -1.7 to 2.4 (mean -0.25 , SD 1.1). Body mass index (BMI) standard deviation score varied from -1.90 to 1.05 (mean -0.30, SD 0.71).

\section{Results}

Measurement of intra-assay precision for the assay of oxalate gave a coefficient of variation (CV) of $9.9 \%$ at $0.17 \mathrm{mmol} / 1$ oxalate and CV of $8.0 \%$ at $1.12 \mathrm{mmol} / 1$ oxalate. Table 1 shows the results of assays for oxalate, glycolate, and calcium. Figure 1 shows the relation between oxalate excretion and calcium excretion; this illustrates that children with high amounts of oxalate excretion were likely to have low amounts of calcium excretion.

Correlations were measured between oxalate excretion and clinical variables, and between calcium excretion and clinical variables. Table 2 shows the results. Oxalate excretion was significantly correlated to age and glycolate excretion, while age and glycolate were not correlated $(r=0.047, \mathrm{p}=0.82)$. These associations persisted when only cases with high oxalate excretion were included (age: $r=0.665$, $\mathrm{p}=0.009$; glycolate: $r=0.602, \mathrm{p}=0.023$; $\mathrm{n}=14$ ). Multiple linear regression was performed using these significant variables for all cases with oxalate excretion as the dependent variable. Table 3 shows the results; age and glycolate excretion were likely to be independently related to oxalate excretion. Figure 2 shows the relation between oxalate excretion and glycolate excretion. There is one outlier with high glycolate excretion. If this data point 
Table 2 Correlation between excretion of solutes and clinical variables

\begin{tabular}{lllllrl}
\hline Variable & $\begin{array}{l}\text { Correlation } \\
\text { oxalate excretion }\end{array}$ & p value & $\begin{array}{l}\text { Correlation } \\
\text { calcium excretion }\end{array}$ & p value & $\begin{array}{l}\text { Correlation } \\
\text { glycolate excretion }\end{array}$ & $p$ value \\
\hline Age & 0.455 & 0.020 & -0.497 & 0.013 & 0.047 & 0.824 \\
BMI SD score & -0.036 & 0.863 & -0.025 & 0.909 & -0.004 & 0.987 \\
Calcium excretion & -0.177 & 0.408 & - & - & -0.060 & 0.785 \\
FEV & 0.095 & 0.653 & 0.081 & 0.715 & -0.148 & 0.489 \\
Glycolate excretion & 0.485 & 0.014 & -0.060 & 0.785 & - & - \\
Lipase dose & -0.363 & 0.081 & -0.103 & 0.648 & -0.157 & 0.474 \\
Oxalate excretion & - & - & -0.177 & 0.408 & 0.485 & 0.014 \\
\hline
\end{tabular}

*Pearson's correlation coefficient; significance levels are two tailed.

Table 3 Results of multiple linear regression for oxalate

\begin{tabular}{llll}
\hline Variable & $\begin{array}{l}\text { Regression } \\
\text { coefficient }\end{array}$ & Standard error & p value \\
\hline Glycolate & 0.637 & 0.221 & 0.009 \\
Age & 0.0273 & 0.010 & 0.011
\end{tabular}

$F=8.371,2$ degrees of freedom, $\mathrm{p}=0.002, \mathrm{R}^{2}=0.432$.

is excluded the correlation between oxalate and glycolate excretion is strengthened $(r=0.760$, $\mathrm{p}<0.001)$. Calcium excretion was significantly correlated with age but not with any other clinical variable.

Of the 14 patients with increased oxalate excretion, 13 had normal amounts of glycolate excretion. The exception was patient 9 who had an oxalate excretion of $1.03 \mathrm{mmol} / 24 \mathrm{~h}$, which was the highest in this survey, and glycolate excretion of $0.59 \mathrm{mmol} / 24 \mathrm{~h}$. Of the 12 patients with normal amounts of oxalate excretion the glycolate was above normal in one patient (patient 19; oxalate excretion 0.35 $\mathrm{mmol} / 24 \mathrm{~h}$, glycolate excretion $0.710 \mathrm{mmol} / 24$ h). No patient had macroscopic nephrocalcinosis or any symptoms suggestive of stone disease.

\section{Discussion}

This study provides a cross sectional view of urinary oxalate excretion in children with cystic fibrosis and no clinical evidence of stone at the time of the collection. Fourteen of 26 children with CF had increased urinary excretion of oxalate during a 24 hour collection of urine. The limitations of this study include: uncontrolled diet; incomplete assay of oxalate loss (faecal loss not accounted for); non-random selection of patients (children with more problems may have had a higher frequency of "rou-

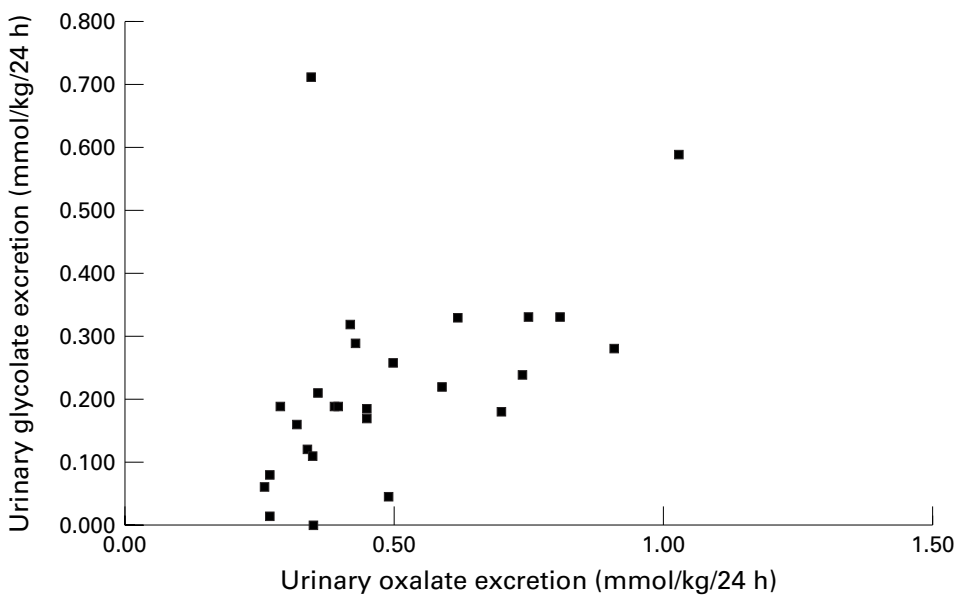

Figure 2 Relation between urinary oxalate excretion and urinary glycolate excretion. tine" clinic visits); lack of data about renal function (as oxalate excretion will depend on glomerular and tubular function); and lack of formal controls (comparisons were made to predefined laboratory ranges for normal populations).

Oxalate is the end product of vitamin C (ascorbic acid) metabolism. ${ }^{9}$ Glycolate is an intermediate in this process. It would be expected that if hyperoxaluria were the result of increased metabolic activity then glycolate excretion in urine would be raised. ${ }^{9}$ On the other hand if hyperoxaluria were secondary to increased uptake then an increase in urinary glycolate would not be expected. In the current study, the urinary glycolate excretion was used as a non-invasive measure of whether the urinary oxalate had a metabolic origin.

The association of oxalate excretion with glycolate excretion (which persisted after statistical adjustment for age) suggests that the excretion of these solutes is linked. As seen in fig 2 , this relation persisted in children with high amounts of oxalate excretion, suggesting that excess oxalate excretion has a metabolic component.

Alternative explanations are not supported by these data.

- The crude markers of malabsorption available from routine clinical notes (lipase dose and BMI SD score) were not correlated with urinary excretion of either oxalate or calcium. At the time of this study lipase dose was determined on the basis of symptoms relating to defaecation, which are relatively poorly linked to the extent of malabsorption.

- The pulmonary marker of disease severity used here, $\mathrm{FEV}_{1}$, was not related to excretion of any of the solutes. However, the subjects were clustered towards relative good health.

- Medication could have altered oxalate excretion. Pyridoxine has been used to reduce urinary oxalate in mild metabolic hyperoxaluria. ${ }^{15}$ As noted, vitamin $\mathrm{C}$ is a source of oxalate ${ }^{9}$; vitamin $\mathrm{C}$ intake could therefore have altered oxalate excretion. Furthermore, high urinary concentrations of ascorbic acid have been shown to enhance stone formation. ${ }^{16}$ During this study all of these patients were on their normal multivitamin preparation (Ketovite) which contains both pyridoxine and ascorbic acid in the tablet form. It seems unlikely that this could explain these results, particularly as half the children have increased oxalate excretion but all the children received multivitamins. 
Our data therefore support the conclusion that at least some of the oxalate excreted by children with $\mathrm{CF}$ has a metabolic origin.

Some clues about the nature of this metabolic process are given by results in individual patients. The index patient was retested as part of the series and found to have normal amounts of excretion of oxalate and glycolate, suggesting that any metabolic process could be transient. Another child had increased excretion of oxalate and glycolate but did not develop renal stones, which suggests that other factors may be involved in the formation of renal stones. One child had normal excretion of oxalate but increased excretion of glycolate which could be due an atypical pattern of ingestion of sugars (for example, xylose ${ }^{17}$ ).

Factors not considered in this study could alter renal stone forming potential in CF. Sidhu et $a l^{10}$ recently reported that a bacterium involved in oxalate metabolism (Oxalobacter formigenes) was frequently present in the stool of healthy controls but infrequently present in the stool of young children with cystic fibrosis; the only child with normal amounts of $O$ formigenes had not received antibiotics prior to the stool collection. We have no data on the presence of this bacterium on our sample and this issue will require further study. Some therapeutic agents used in CF could influence stone formation: gentamicin enhances oxalate crystal formation ${ }^{18}$ and damages urothelium which can enhance stone formation ${ }^{19}$ (none of these patients was on an aminoglycoside during the urine collections); high dietary intake of sodium increases calcium excretion ${ }^{20}$ (none of our patients received salt supplementation during the urine collections).

In conclusion, the current report is the first study to relate urinary excretion of oxalate and the simultaneous urinary excretion calcium in 24 hour urine samples from children with $\mathrm{CF}$, and to relate the excretion of each compound to that of the other in the same child. We have shown that 15 of 24 children with $\mathrm{CF}$ had reduced amounts of urinary calcium excretion, including several children with amounts of oxalate excretion high enough to risk stone formation. It is possible that the reduced level of urinary calcium excretion is protecting children with hyperoxaluria from forming renal stones.

Altered renal handling of calcium in cystic fibrosis could reflect several factors such as reduced uptake caused by deficiency of vitamin $\mathrm{D}$ or transport defects in the kidney. A direct effect of alterations in calcium handling by the CF kidney cannot be excluded in the light of recent work that shows that other defects in ion transport affecting sodium ${ }^{21}$ or chloride ${ }^{22}$ also affect calcium excretion.

Dr Barbara Phillips and the late Mr Ian Ward identified the clinical issue and intitiated the study. We are grateful to Manchester Grammar School for providing funding for the purchase of reagents. Glycolate estimations were carried out by purchase of reagents. Glycolate estimations were carried out by
the Department of Biochemistry, University College London to whom we are grateful.

1 Euler AR, Ament ME. Crohn's disease a cause of arthritis, oxalate stones and fistulae in cystic fibrosis. West $7 \mathrm{Med}$ 1976;125:315-17.

2 Holcslaw Jr DB, Lerner A, Lem C, Kreuger LJ. Nephrolithiasis in cystic fibrosis. Proceedings of 1990 CF Conference. Bethesda, MD: Cystic Fibrosis Foundation, 1990:290.

3 Strandvik B, Hjelte L. Nephrolithiasis in cystic fibrosis. Acta Paediatr Scand 1993;82:306-7.

4 Chidekel AS, Dolan TFJ. Cystic fibrosis and calcium oxalate nephrolithiasis. Yale f Biol Med 1996;69:317-21.

5 Bohles H, Michalk D. Is there a risk for kidney stone formaBohles H, Michalk D. Is there a risk for kidney stone forma-
tion in cystic fibrosis? Helv Paediatr Acta 1982;37:267-72. tion in cystic fibrosis? Helv Paediatr Acta 1982;37:267-72.
Katz SM, Kreuger LJ, Falkner B. Microscopic nephrocalciKatz SM, Kreuger LJ, Falkner B. Microscopic nephrocalc
nosis in cystic fibrosis. N Engl f Med 1988;349:263-6.

7 Bentur L, Kerem E, Couper R, et al. Renal calcium handling in cystic fibrosis: lack of evidence for a primary renal defect. F Pediatr 1990;116:556-60.

8 Nightingale JMD. The short-bowel syndrome. Eur f Gastroenterol Hepatol 1995;7:514-20.

9 Rampton DS, Sarner M. Enteric and other secondary hyperoxalurias. In: Rose GA, ed. Oxalate metabolism in relation to urinary stone. London: Springer-Verlag, 1988:10319.

10 Sidhu H, Hoppe B, Hesse A, Tenbrock K, Brömme S, Rietschel E, Peck AB. Absence of Oxalobacter formigenes in cystic fibrosis patients: a risk factor for hyperoxaluria. Lancet 1998;352:1026-9.

11 Koolstra W, Wolthiers BG, Hayes M, Rutgers HM. An improved high performance liquid chromatographic method for determining urinary oxalate making use of an method for determining urinary oxalate making use of an 44 .

12 Kasides GP, Rose GA. A new enzymatic method for the determination of glycolate in urine and plasma. Clin Chim Acta 1979;96:25-36.

13 Freeman JV, Cole TJ, Chinn S, Jones PRM, White EM, Preece MA. Cross sectional stature and weight reference curves for the UK, 1990. Arch Dis Child 1995;73:17-24.

14 Cole TJ, Freeman JV, Preece MA. Body mass index reference curves for the UK, 1990. Arch Dis Child 1995;73: $25-9$.

15 Rose GA. Mild metabolic hyperoxaluria. A new syndrome. In: Rose GA, ed. Oxalate metabolism in relation to urinary stone. London: Springer-Verlag, 1988:121-30.

16 Singh PP, Kiran R, Pendse AK, Ghosh R, Surana SS. Ascorbic acid as an abettor in calcium urolithiasis: an bic acid as an abettor in calcium urolithiasis:

17 McWhinney BC, Nagel SL, Cowley DM, Brown JM, Chalmers $\mathrm{AH}$. Two-carbon oxalogenesis compared in
recurrent calcium oxalate stone formers and normal recurrent calcium oxalate stone form

18 Finlayson B, Khan SR, Hackett RL. Gentamicin accelerates calcium oxalate monohydrate nucleation. In: Walker VR, Sutton RAL, Cameron ECB, Pak CYC, eds. Urolithiasis. New York: Plenum Press, 1989:59-60.

19 Khan SR. Calcium oxalate crystal interaction with renal tubular epithelium, mechanism of crystal adhesion and its impact on stone development. Urol Res 1995;23:71-9.

20 Massey LK, Whiting SJ. Dietary salt, urinary calcium and kidney stone risk. Nutr Rev 1995;53:131-9.

21 Dillon MJ. Advances in sodium homeostasis. In: David TJ, ed. Recent advances in paediatrics. New York: Churchill Livingstone, 1998:183-94.

22 Lloyd SE, Pearce SHS, Fisher SE, et al. A common molecular basis for three inherited kidney stone diseases. Nature 1996;379:445-9. 